\title{
Effect of sludge on germination and growth of bioenergy crops
}

\author{
Mahmoud F. Seleiman, Pirjo Mäkelä, Arja Santanen and Fredrick Stoddard \\ Department of Agricultural Sciences, P.O. Box 27, FIN-00014 University of Helsinki, Finland, \\ mahmoud.seleiman@helsinki.fi
}

Sludge is a good source of plant nutrients, but its use as fertilizer for food or fodder crops is questionable due to its potential content of heavy metals and metalloids.

In two pot experiments, germination and growth of maize (Zea mays L., cv. Ronaldino), fiber hemp (Cannabis sativa L., cv. Uso 31) and oilseed rape (Brassica napus L. ssp. oleifera (DC.) Metzg., cv.Wildcat) were studied when treated with sewage sludge and biogas sludge in comparison with chemical fertilizer during 2011. The experiment included five treatments: soil+sewage sludge, soil+fertilizer, sand mixed with peat+sewage sludge, sand mixed with peat+fertilizer, and soil+biogas sludge. Sludge content was calculated to deliver the same content of nitrogen that was added for each species. Germination percentage was recorded at 7, 10 and 14 days after sowing. Length and dry weight of roots and shoots were measured at 14 days after sowing for all species.

Sewage sludge treatments resulted in higher germination percentage compared to biogas sludge and fertilizer application in soil and sand mixed with peat. The longest roots were in the sewage sludge treatment. In addition, shoot lengths in maize were highest when fertilized with sludge or fertilizer in soil. Furthermore, sewage sludge or fertilizer added to soil increased root and shoot dry weight of maize.

In conclusion, there is an existing excellent potential for using sewage sludge not only as organic matter but also as a valuable plant nutrient source for improving growth of bioenergy crops.

Keywords: Sewage sludge, biogas sludge, germination, maize, oilseed rape, hemp 


\section{Introduction}

Sludge is rich in nutrients such as nitrogen and phosphorous and contains valuable organic matter. The organic matter and nutrients in sludge are considered as the two factors that make sewage sludge potentially suitable as a fertilizer in agriculture production. Many studies have indicated that sewage sludge can be effectively used as a fertilizer for crop yield and improving physical and chemical properties of soils (Subbiah and Ramulu, 1980; Qasim et al., 2001). Christodoullakis \& Margaris (1996) reported that sewage sludge application improved maize growth in comparison to synthetic fertilizer, increasing plant height by $77 \%$ while synthetic fertilizer increased plant height by $25 \%$ compared to plants under control treatment. Wilkins (1957) reported that root elongation is a sensitive measure of the ability of plants to grow in soil that contains heavy metal (particularly lead).

The objective of this work was to study the effect of sewage sludge, biogas sludge and chemical fertilizer applications on germination percentage and length and dry weight of shoot and root of maize, fiber hemp and oilseed rape.

\section{Materials and Methods}

Two pot experiments were conducted in the glasshouse, during 2011, with maize (Zea mays L., cv. Ronaldino), fiber hemp (Cannabis sativa L., cv. Uso 31) and oilseed rape (Brassica napus L. ssp. oleifera (DC.) Metzg., cv.Wildcat). One hundred seeds were sown in each pot containing $5 \mathrm{~kg}$ soil or $4.5 \mathrm{~kg}$ sand mixed with unfertilized peat. The experiment included five treatments: soil+sewage sludge, soil+fertilizer, sand mixed with peat+sewage sludge, sand mixed with peat+fertilizer, and soil+biogas sludge. Sewage sludge and biogas sludge additions were calculated to deliver the same amount of nitrogen for each species. Growth conditions were day length $18 / 6 \mathrm{~h}$, temperature $21 / 19^{\circ} \mathrm{C}$ and constant relative humidity $50 \%$. Experiments were arranged in a randomized complete block design with three replicates.

Germination percentage was recorded at 7,10 and 14 days after sowing and the following measurements were made at 14 days after sowing) :

1. Root length $(\mathrm{cm})$,

2. Shoot length $(\mathrm{cm})$,

3. Root dry weight (g) and

4. Shoot dry weight (g).

\section{Results and discussion}

There were no significant differences in germination percentage between treatments. The highest germination percentages were obtained from plant grown in soil and sand treated with sewage sludge ( 98.3 and $97.7 \%$, respectively). There were no differences between sludge and fertilizer treatments when plants were grown in soil (Figures 1 and 2). However, when plants were grown in sand, the sewage sludge application provided better growth than the fertilizer, showing that sewage sludge could provide plants with adequate nutrition. Qasim et al. (2001) found that an increasing rate of sewage sludge application resulted in a significant increase in shoot and root length and shoot and root dry weight of maize plants, but that there was no significant effect of increased sludge application on germination percentage, similarly to our findings. In addition, Amin and Sherif (2001) reported that increasing sludge rates significantly increased several growth parameters. 


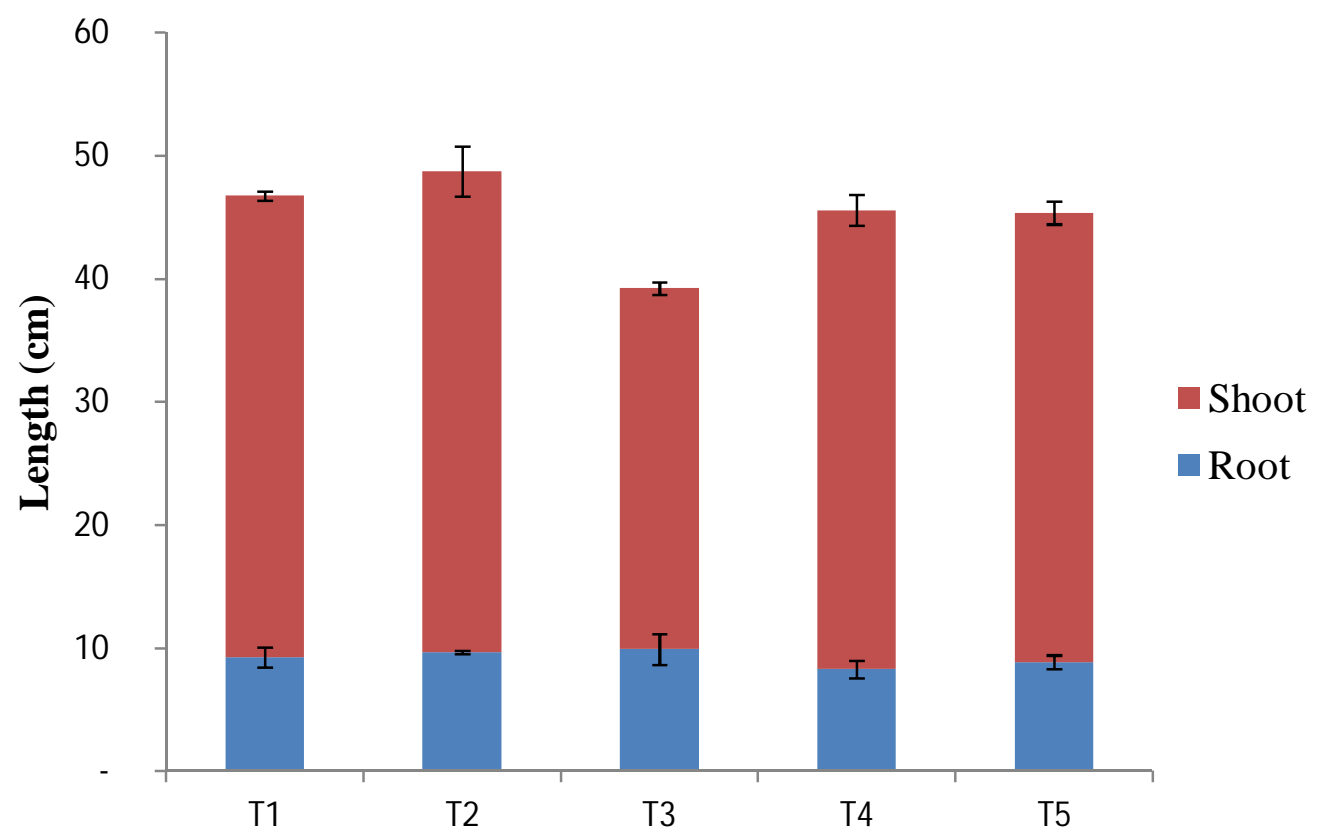

Figure 1. Effect of sewage sludge, fertilizer and biogas sludge on root and shoot length $(\mathrm{cm})$ of maize. T1, soil + sewage sludge; T2, soil + fertilizer; T3, sand mixed with peat + sludge; T4, sand mixed with peat + fertilizer; 75 , soil + biogas sludge. Data shown are means \pm SE.

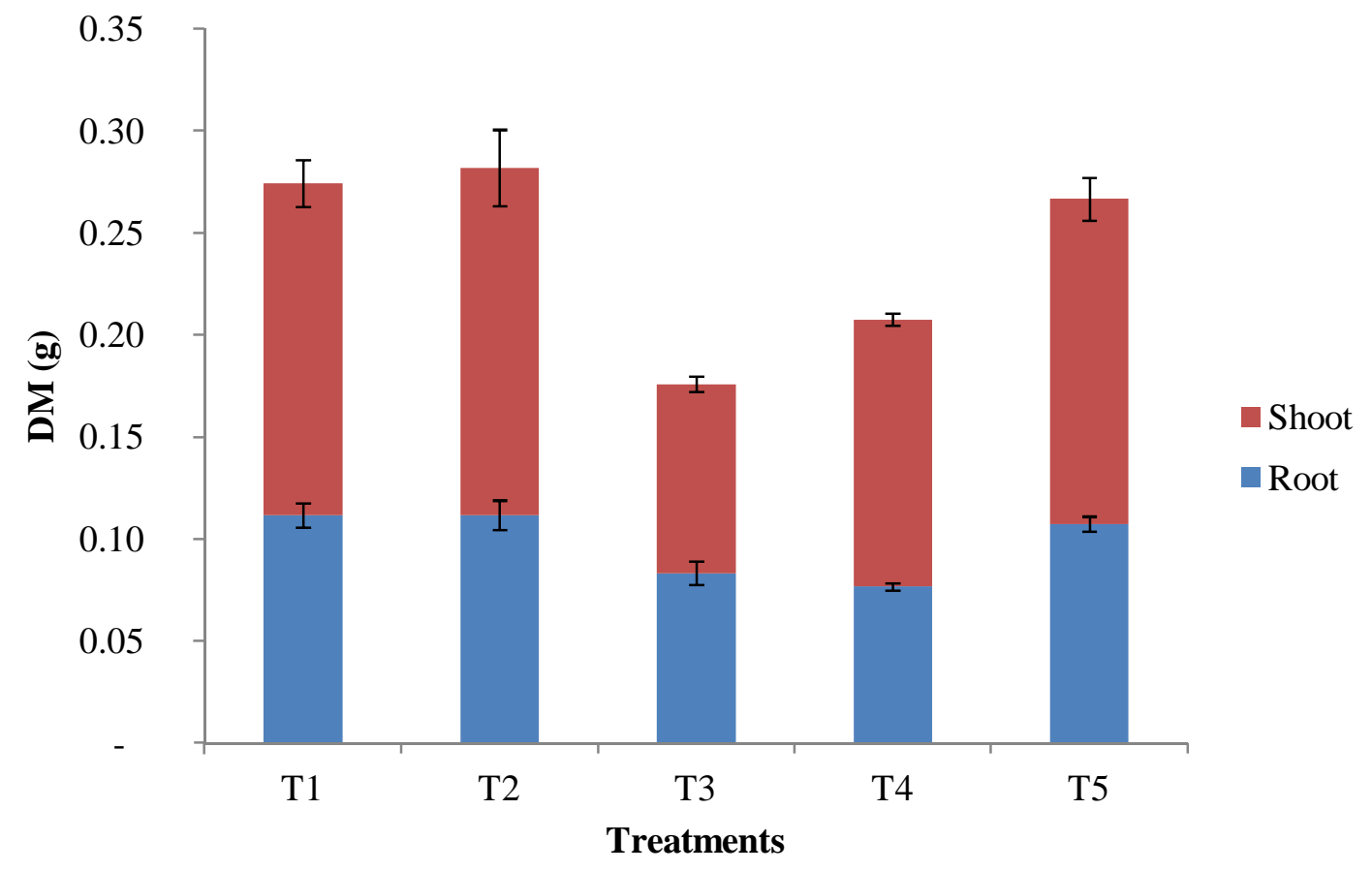

Figure 2. Effect of sewage sludge, fertilizer and biogas sludge on root and shoot dry weight of maize. T1, soil + sewage sludge; T2, soil + fertilizer; T3, sand mixed with peat + sludge; T4, sand mixed with peat + fertilizer; T5, soil + biogas sludge. Data shown are means \pm SE.

\section{References}

Amin, A.W. \& Sherif, F.K. 2001. Heavy metals in maize as affected by sewage sludge application: 1- Morphological characters and yield. Pakistan Journal of Biological Sciences 4: 1451-1455. 
Christodoulakis, N. \& Margaris, S. 1996. Growth of corn and sunflower plants as affected by water and sludge from a sewage treatment plant. Bulletin of Environmental Contamination and Toxicology 57: 300-306.

Qasim, M., Himayatullah, N. \& Subhan, M. 2001. Effect of sewage sludge on the growth of maize crop. Journal of Biological Sciences 1: 52-54.

Subbia, S. \& Ramulu, S. 1980. The effect of anaerobically digested sewage sludge on organic fraction of clay loam soil. Mysore Journal of Agricultural Sciences 14: 301-301.

Wilkins, D. 1957. A technique for the measurement of lead tolerance in plants. Nature 180: 37. 